\title{
Prevention of hypotension during induction of anesthesia with propofol and fentanyl: Comparison of preloading with crystalloid and intravenous ephedrine.
}

\author{
Vikas Dutta ${ }^{1}$, Mubasher Ahmad ${ }^{2}$, Showkat Gurcoo ${ }^{3}$, Muhammad Ommid $^{4} \&$ \\ Muhammad Syed Qazi ${ }^{5}$ \\ 1, 2, 3, 5 (Anaesthesiology and Critical Care, Sher-i-Kashmir institute of Medical Science Srinagar India \\ ${ }^{4}$ (Anaesthesiology, Government medical college Srinagar, India)
}

\begin{abstract}
In this study, we compared the effect of preloading with crystalloid and intravenous ephedrine against the hypotensive effects of propofol and fentanyl induction in ASA I-II patients scheduled for elective surgical procedures. 150 patients aged 18yrs to 60yrs were randomly allocated to one of the three groups of 50 patients each. Group-A (control) did not receive any study medication, group-B received Ringers lactate $20 \mathrm{ml} / \mathrm{kg}$ over 10-15min and group-C received intravenous ephedrine $0.2 \mathrm{mg} / \mathrm{kg}$ prior to induction of anesthesia. Anesthesia was induced with propofol $2.5 \mathrm{mg} / \mathrm{kg}$, fentanyl $1.5 \mu \mathrm{g} / \mathrm{kg}$ and atracurim $0.5 \mathrm{mg} / \mathrm{kg}$. Heart rate and blood pressure were recorded before induction and then every min for 5 min after induction of anesthesia. After the study period patients were intubated and anesthesia was continued as required. Hypotension was defined as a drop in systolic arterial pressure more than or equal to $20 \%$ of baseline. A significant decrease in systolic arterial pressure occurred in both the fluid loaded and the control group. Least decrease in systolic arterial pressure was seen in the ephedrine group. The incidence of hypotension was also lower in ephedrine group when compared with control group. We conclude that crystalloid preloading is not efficacious in preventing hypotension and ephedrine markedly attenuates, but does not fully abolish, the decrease in blood pressure caused by propofol and fentanyl induction.
\end{abstract}

Keywords: propofol, fentanyl, preloading and ephedrine.

\section{Introduction}

Propofol (2,6 diisopropylphenol) is a rapidly acting IV anesthetic agent widely used for induction of general anesthesia ${ }^{[1]}$. Fentanyl is commonly used as a short acting analgesic agent with propofol. The induction of general anesthesia with propofol, however, has been associated with a decrease in systolic arterial pressure ${ }^{[2]}$. The mechanism of this hypotension is not well understood. The hypotensive effects of propofol has been attributed to a decrease in systemic vascular resistance caused by combination of venous and arterial vasodilatation ${ }^{[3]}$. Depression of myocardial contractility and impaired baroreflex mechanism also play a role ${ }^{[4,5]}$. The cardiovascular depressant effects of propofol are increased when fentanyl is added ${ }^{[6]}$. Various strategies have been attempted to prevent this hypotension with inconclusive evidence. Ketamine, ephedrine, atropine, glycopyrrolate, dopamine, dobutamine and metaraminol have been administered in various studies to prevent this hypotension, with variable results ${ }^{[7-10]}$. Fluid preloading with colloid and crystalloid has also been used to prevent the hypotensive effects of induction of anesthesia with these drugs ${ }^{[11,12]}$.

The present study was undertaken to compare, the effect of preloading with crystalloid (Ringer lactate) and the effect of prophylactic administration of intravenous ephedrine against the hypotensive effects of induction of anesthesia with propofol and fentanyl.

\section{Patients and methods}

After obtaining approval from the hospital ethics committee and informed consent we studied 150 patients, ASA I or II, scheduled for elective surgical procedures under general anesthesia. Patients with history of any cardiac, cerebrovascular, respiratory, endocrine, hepatic or renal disease were excluded from the study. Patients allergic to study medication, taking any drugs affecting heart rate or blood pressure, patients with anticipated difficult airway, morbid obesity (BMI>35) and pregnant females were also excluded. Patients were allocated using sealed envelope technique into three groups, to receive, no drug or fluid preload (Control groupgroup-A), $20 \mathrm{ml} / \mathrm{kg}$ of ringers lactate over15-20min (Crystalloid group-group-B), or $0.2 \mathrm{mg} / \mathrm{kg}$ of ephedrine (Ephedrine group-group-C).

The patients received no premedication. In the anesthetic room, intravenous access was established using a 18 gauge cannula. The usual maintenance and replacement fluid (normal saline) was started at the rate of $2 \mathrm{ml} / \mathrm{kg}$ in all the patients. On shifting the patient to the operating room, routine monitoring i.e. 
Prevention of hypotension during induction of anesthesia with propofol and fentanyl: Comparison electrocardiography, heart rate, pulse oximetry and NIBP was established. Baseline cardiovascular parameters i.e. heart rate, blood pressure (systolic, diastolic and mean) and oxygen saturation were recorded. Noninvasive blood pressure was measured by using Datex-Engstrom Cardiocap II monitor. Patients allocated to receive a fluid preload were infused over $20 \mathrm{~min}$ with ringers lactate, $20 \mathrm{ml} / \mathrm{kg}$. Patients allocated to ephedrine group received ephedrine $0.2 \mathrm{mg} / \mathrm{kg}$ just prior to induction.

Anesthesia was induced with fentanyl $1.5 \mu \mathrm{g} / \mathrm{kg}$ followed by propofol $2.5 \mathrm{mg} / \mathrm{kg}$ injected over 30sec. Patients were given atracurium besylate $0.5 \mathrm{mg} / \mathrm{kg}$ as muscle relaxant. We measured the heart rate, arterial blood pressure (systolic, diastolic and mean) and oxygen saturation every minute, starting $1 \mathrm{~min}$ after induction till $5 \mathrm{~min}$ after propofol injection. In this period, bag and mask ventilation was used to maintain oxygen saturation greater than $95 \%$ and no endotracheal intubation was done. After the study period patients were intubated and anesthesia was continued as required. Hypotension was defined as a drop in systolic arterial pressure more than or equal to $20 \%$ of baseline. Hypotension was treated with rapid infusions of ringers lactate.

The statistical analysis of categorical data was done by using Chi-square test. The quantitative data of the three groups was analyzed by using one way analysis of variance (ANOVA). All tests were referred for Pvalues for their significance. Any P-value less than $0.05(\mathrm{P}<0.05)$ was taken to be statistically significant. Data was presented as mean $( \pm \mathrm{SD})$. The analysis of data was performed using comprehensive statistical software i.e. statistical package for social sciences (SPSS ver. 17.0), Chicago, USA for windows.

\section{Results}

150 patients were recruited to the study. All the groups were comparable with respect to age and body weight. The three groups were comparable with regard to baseline hemodynamic variables (TABLE 1).

Table-1: Demographic data and baseline hemodynamic parameters.

\begin{tabular}{|l|c|c|c|c|}
\hline \multicolumn{1}{|c|}{ Parameters } & $\begin{array}{c}\text { Group-A } \\
\text { mean } \pm \text { SD }\end{array}$ & $\begin{array}{c}\text { Group-B } \\
\text { mean } \pm \text { SD }\end{array}$ & $\begin{array}{c}\text { Group-C } \\
\text { mean } \pm \text { SD }\end{array}$ & P value \\
\hline Age(years) & $39.48 \pm 10.84$ & $40.78 \pm 9.61$ & $40.76 \pm 11.25$ & 0.80 \\
\hline Weight(kg) & $59.18 \pm 8.13$ & $63.08 \pm 6.68$ & $60.80 \pm 7.86$ & 0.13 \\
\hline Heart rate(beats/min) & $89.06 \pm 9.59$ & $88.26 \pm 13.30$ & $85.70 \pm 12.40$ & 0.33 \\
\hline $\begin{array}{l}\text { Systolic blood } \\
\text { pressure(mmHg) }\end{array}$ & $126.36 \pm 5.12$ & $124.08 \pm 8.51$ & $123.30 \pm 8.48$ & 0.15 \\
\hline $\begin{array}{l}\text { Diastolic blood } \\
\text { pressure(mmHg) }\end{array}$ & $76.50 \pm 3.91$ & $75.98 \pm 7.06$ & $77.46 \pm 7.94$ & 0.13 \\
\hline Mean arterial pressure $(\mathrm{mmHg})$ & $93.18 \pm 3.64$ & $92.14 \pm 7.16$ & $92.86 \pm 7.85$ & 0.11 \\
\hline
\end{tabular}

Systolic blood pressure (SBP) decreased in all the three groups after the induction of anesthesia. The drop in systolic blood pressure over the study period was similar in group-A and group-B. In group-A SBP decreased to $95 \mathrm{mmHg}$ at $5 \mathrm{~min}$ ( $75 \%$ of the baseline), in group-B SBP decreased to $97 \mathrm{mmHg}$ (78\% of the baseline) and in group-C systolic blood pressure decreased to $103 \mathrm{mmHg}$ ( $84 \%$ of the baseline). The decrease in systolic blood pressure was highest in group-A and the lowest in group-C (TABLE 2).

Table-2: Comparison of systolic blood pressure during the study period.

\begin{tabular}{|c|c|c|c|c|}
\hline $\begin{array}{c}\text { Time } \\
(\text { min) }\end{array}$ & $\begin{array}{c}\text { Group-A } \\
\text { mean } \pm \text { SD }\end{array}$ & $\begin{array}{c}\text { Group-B } \\
\text { mean } \pm \text { SD }\end{array}$ & $\begin{array}{c}\text { Group-C } \\
\text { mean } \pm \text { SD }\end{array}$ & P value \\
\hline Baseline & $126.36 \pm 5.12$ & $124.08 \pm 8.51$ & $123.30 \pm 8.48$ & 0.15 \\
\hline 1 & $102.36 \pm 7.10$ & $105.38 \pm 8.91$ & $106.56 \pm 12.76$ & 0.01 \\
\hline 2 & $93.28 \pm 8.67$ & $96.58 \pm 8.72$ & $98.94 \pm 13.39$ & 0.01 \\
\hline 3 & $94.12 \pm 8.60$ & $95.72 \pm 15.26$ & $100.28 \pm 8.30$ & 0.03 \\
\hline 4 & $95.38 \pm 6.87$ & $96.68 \pm 13.65$ & $100.40 \pm 6.31$ & 0.04 \\
\hline 5 & $95.38 \pm 6.55$ & $97.22 \pm 9.73$ & $103.72 \pm 5.44$ & 0.00 \\
\hline
\end{tabular}

Decrease in diastolic blood pressure (DBP) and mean arterial pressure (MAP) was also compared. DBP and MAP were similar in group-A and group-B. There were no significant differences in DBP and MAP between group-A and group-B. The decrease in DBP in group-A and group-B was similar and more than groupC. At $5 \mathrm{~min}$ the DBP was statistically comparable among the three groups (TABLE 3). 
Prevention of hypotension during induction of anesthesia with propofol and fentanyl: Comparison

Table-3: Comparison of diastolic blood pressure during the study period

\begin{tabular}{|c|c|c|c|c|}
\hline $\begin{array}{c}\text { Time } \\
(\mathbf{m i n})\end{array}$ & $\begin{array}{c}\text { Group-A } \\
\text { mean } \pm \text { SD }\end{array}$ & $\begin{array}{c}\text { Group-B } \\
\text { mean } \pm \text { SD }\end{array}$ & $\begin{array}{c}\text { Group-C } \\
\text { mean } \pm \text { SD }\end{array}$ & P-value \\
\hline Baseline & $79.68 \pm 5.98$ & $75.98 \pm 7.06$ & $77.46 \pm 7.94$ & 0.13 \\
\hline 1 & $56.22 \pm 6.97$ & $55.72 \pm 7.03$ & $58.14 \pm 9.82$ & 0.02 \\
\hline 2 & $48.64 \pm 10.40$ & $49.38 \pm 7.54$ & $51.58 \pm 8.33$ & 0.02 \\
\hline 3 & $48.68 \pm 5.07$ & $48.10 \pm 8.52$ & $51.34 \pm 4.30$ & 0.04 \\
\hline 4 & $48.94 \pm 4.38$ & $49.60 \pm 11.69$ & $54.76 \pm 5.40$ & 0.00 \\
\hline 5 & $53.30 \pm 5.37$ & $53.48 \pm 8.05$ & $53.66 \pm 5.32$ & 0.08 \\
\hline
\end{tabular}

MAP decreased in all the three groups after the induction of anesthesia. The decrease was similar in group-A and group-B. The decrease in MAP in group-C was significantly less when compared to group-A and group-B

(TABLE-4).

Table-4: Comparison of mean arterial pressure during the study period.

\begin{tabular}{|c|c|c|c|c|}
\hline $\begin{array}{c}\text { Time } \\
(\text { min) }\end{array}$ & $\begin{array}{c}\text { Group-A } \\
\text { mean } \pm \text { SD }\end{array}$ & $\begin{array}{c}\text { Group-B } \\
\text { mean } \pm \text { SD }\end{array}$ & $\begin{array}{c}\text { Group-C } \\
\text { mean } \pm \text { SD }\end{array}$ & P-value \\
\hline Baseline & $93.18 \pm 3.64$ & $92.14 \pm 7.16$ & $92.86 \pm 7.85$ & 0.11 \\
\hline 1 & $72.36 \pm 7.04$ & $73.98 \pm 7.45$ & $73.80 \pm 10.23$ & 0.01 \\
\hline 2 & $63.56 \pm 8.92$ & $64.88 \pm 7.32$ & $66.74 \pm 9.60$ & 0.02 \\
\hline 3 & $63.86 \pm 5.18$ & $63.70 \pm 10.03$ & $66.92 \pm 4.23$ & 0.04 \\
\hline 4 & $64.64 \pm 4.43$ & $65.24 \pm 11.89$ & $69.62 \pm 4.11$ & 0.02 \\
\hline 5 & $68.52 \pm 4.92$ & $67.78 \pm 7.16$ & $69.78 \pm 4.75$ & 0.01 \\
\hline
\end{tabular}

Baseline heart rate (HR) was comparable in the three groups. In group-A and group-B it decreased following anesthetic induction. In group-C it increased from baseline following anesthetic induction (TABLE$5)$.

Table-5: Comparison of heart rate during the study period.

\begin{tabular}{|c|c|c|c|c|}
\hline $\begin{array}{c}\text { Time } \\
\text { (min) }\end{array}$ & $\begin{array}{c}\text { Group-A } \\
\text { mean } \pm \text { SD }\end{array}$ & $\begin{array}{c}\text { Group-B } \\
\text { mean } \pm \text { SD }\end{array}$ & $\begin{array}{c}\text { Group-C } \\
\text { mean } \pm \text { SD }\end{array}$ & P-value \\
\hline Baseline & $89.06 \pm 9.59$ & $88.26 \pm 13.30$ & $85.70 \pm 12.40$ & 0.33 \\
\hline 1 & $90.46 \pm 12.58$ & $89.72 \pm 18.98$ & $87.16 \pm 9.91$ & 0.48 \\
\hline 2 & $79.38 \pm 11.94$ & $77.78 \pm 15.68$ & $89.74 \pm 7.19$ & 0.00 \\
\hline 3 & $78.98 \pm 14.92$ & $73.98 \pm 15.25$ & $85.06 \pm 7.26$ & 0.00 \\
\hline 4 & $74.82 \pm 12.29$ & $71.16 \pm 12.42$ & $84.48 \pm 7.45$ & 0.00 \\
\hline 5 & $74.84 \pm 12.59$ & $73.86 \pm 12.71$ & $88.46 \pm 8.57$ & 0.00 \\
\hline
\end{tabular}

The incidence of hypotension in the three groups during the study period was also compared. The number of patients developing hypotension at $1 \mathrm{~min}$ was not significant when compared among the three groups $(\mathrm{P}>0.05)$. The incidence of hypotension was significant at $2 \mathrm{~min}, 3 \mathrm{~min}, 4 \mathrm{~min}$ and $5 \mathrm{~min}(\mathrm{P}<0.05)$. The incidence of hypotension during the study period was highest in group-A followed by group-B and group-C (TABLE-6).

Table-6: Number of patients developing hypotension and time of onset on hypotension.

\begin{tabular}{|c|c|c|c|c|}
\hline \multirow[b]{2}{*}{ Time } & \multicolumn{3}{|c|}{ Number of patients developing hypotension } & \multirow[b]{2}{*}{$P$ value } \\
\hline & Group-A & Group-B & Group-C & \\
\hline $1 \mathrm{~min}$ & $11(22 \%)$ & $10(20 \%)$ & $9(18 \%)$ & 0.13 \\
\hline $2 \mathrm{~min}$ & $42(84 \%)$ & $26(52 \%)$ & $22(44 \%)$ & 0.00 \\
\hline $3 \mathrm{~min}$ & $42(84 \%)$ & $26(52 \%)$ & $23(46 \%)$ & 0.00 \\
\hline $4 \mathrm{~min}$ & $41(82 \%)$ & $26(52 \%)$ & $18(36 \%)$ & 0.00 \\
\hline $5 \mathrm{~min}$ & $36(72 \%)$ & $27(54 \%)$ & $10(20 \%)$ & 0.00 \\
\hline
\end{tabular}

\section{Discussion}

The present study confirms that induction of anesthesia with propofol and fentanyl in ASA-I and II patients is often associated with significant systemic arterial hypotension. The infusion of $20 \mathrm{ml} / \mathrm{kg}$ of crystalloid preload does not prevent or attenuate the decrease in blood pressure after induction of anesthesia with propofol 
Prevention of hypotension during induction of anesthesia with propofol and fentanyl: Comparison and fentanyl. Preinduction IV injection of ephedrine $0.2 \mathrm{mg} / \mathrm{kg}$ significantly attenuated, but did not fully abolish the decrease in blood pressure.

Hypotension after induction of anesthesia with propofol is well recognized ${ }^{[2]}$. The cause of this hypotension has been found to be a reduced systemic vascular resistance and a depression of myocardial contractility ${ }^{[13]}$. Fentanyl was used to supplement induction of anesthesia with propofol. Fentanyl in low doses has minimal cardiovascular effects ${ }^{[14]}$. However when used with propofol for induction of anesthesia it may accentuate the hypotensive and bradycardic effects of propofol ${ }^{[6]}$. Significant decrease in systolic blood pressure from the baseline was observed in all the groups after propofol administration in our study also.

Our findings are consistent with the findings of Turner et al ${ }^{[11]}$ and Al-Ghamdi ${ }^{[15]}$ who have shown lack of full effectiveness of preloading with crystalloid or colloids in preventing hypotension associated with propofol. In the studies conducted by Kumar et al ${ }^{[12]}$ and Dhungana et $\mathrm{al}^{[16]}$ it was observed that fluid preloading attenuated the drastic fall of blood pressure but did not completely abolish the hypotension associated with propofol induction.

In our study, we observed that prophylactic IV ephedrine was more effective than crystalloid preloading in preventing the hypotension during propofol induction. But, ephedrine did not completely abolish the decrease in blood pressure associated with induction of anesthesia with propofol and fentanyl. The results in the present study are comparable to those of Michelsen et a ${ }^{[17]}$. They found that prophylactic IV ephedrine $0.2 \mathrm{mg} / \mathrm{kg}$ significantly attenuated, but did not abolish, the decrease in blood pressure during propofol and fentanyl induction. Gamlin et al ${ }^{[18]}$ found that 15 or $20 \mathrm{mg}$ of ephedrine premixed with $20 \mathrm{ml}$ of $1 \%$ propofol maintained blood pressure at preinduction values, whereas ephedrine $10 \mathrm{mg}$ was insufficient. Similarly, ElBeheiry et $\mathrm{al}^{[19]}$ found that ephedrine $0.07 \mathrm{mg} / \mathrm{kg}$ given just before propofol induction and subsequent tracheal intubation maintained blood pressure at preinduction values for up to $6 \mathrm{~min}$ after induction. The reason that a smaller dose of ephedrine is effective depends on the sympathoadrenal-stimulating effect of intubation.

Although preinduction ephedrine attenuated the hypotensive effects of propofol, some patients still experienced a decrease in blood pressure to $<80 \%$ of baseline. The reason for this may be that ephedrine mainly maintains the blood pressure by increasing the cardiac output ${ }^{[20]}$, whereas propofol, under conditions similar to those in the present study, causes arterial hypotension by reducing peripheral vascular resistance ${ }^{[21,2]}$.

In our study, we observed decrease in heart rate in control group and crystalloid group whereas heart rate increased in the ephedrine group. Turner et a ${ }^{[11]}$ reported decrease in heart rate in non fluid preloaded and fluid preloaded patients after induction of anesthesia with propofol. Kumar et $\mathrm{al}^{[12]}$ observed that heart rate decreased in crystalloid preloaded patients after induction of anesthesia with propofol and fentanyl. In our study, we observed increase in the heart rates in patients receiving ephedrine but it was less than $10 \%$ of the baseline and statistically insignificant. Gamlin et $\mathrm{al}^{22]}$ reported marked tachycardia associated with the use of ephedrine in combination with propofol in majority of patients. The difference in observations could be correlated with higher doses of ephedrine (20 and $25 \mathrm{mg})$ in their study than in ours $(0.2 \mathrm{mg} / \mathrm{kg})$. Dhungana et al ${ }^{[16]}$ also reported insignificant increases in heart rate in patients receiving ephedrine.

In conclusion we found that the administration of crystalloid preload does not prevent the decrease in arterial blood pressure after induction of anesthesia with propofol and fentanyl. The prophylactic intravenous injection of ephedrine $0.2 \mathrm{mg} / \mathrm{kg}$ significantly attenuated, but did not abolish, the decrease in systolic blood pressure associated with induction of anesthesia with propofol and fentanyl.

\section{References}

[1] Smith I, White PF, Nathanson M, et al. Propofol: an update on its clinical use. Anesthesiology 1994;81:1005-1043.

[2] Fairfield JE, Dritsas A and Beale RJ. Hemodynamic effects of propofol: induction with $2.5 \mathrm{mg} / \mathrm{kg}$. British Journal of Anesthesia 1991;67:618-620.

[3] Muzi M, Berens RA, Kampine JP, Ebert TJ. Venodilation contributes to propofol mediated hypotension in humans. Anesthesia and Analgesia 1992;74:877-883

[4] Robinson BJ, Ebert TJ, O’Brien TJ, Colinco MD, Muzi M. Mechanisms whereby propofol mediates peripheral vasodilation in humans. Sympathoinhibition or direct vascular relaxation? Anesthesiology 1997;86:64-72.

[5] Cullen PM, Turtle M, Prys-Roberts C, Way WL, Dye J. Effect of propofol anesthesia on baroreflex activity in humans. Anesthesia and Analgesia 1187;66:1115-1120.

[6] Van Aken H, Meinshausen E, Prien T, Brussel T, Heineake A, Lawin P. The influence of fentanyl and tracheal intubation on the hemodynamic effects of anesthesia induction with propofol/N2O in humans. Anesthesiology 1988;68:157-163.

[7] Ozkocak I, Altunkaya H, Ozer Y, Ayoolu H, Demirel CB, Cicek E. Comparison of ephedrine and ketamine in prevention of injection pain and hypotension due to propofol induction. European Journal of Anesthesiology 2005;22:44-48

[8] Skues MA, Richards MJ, Jarvis AP, Prys-Roberts C. Preinduction atropine or glycopyrrolate and hemodynamic changes associated with induction and maintenance of anesthesia with propofol and alfentanil. Anesthesia and Analgesia 1989;69(3):386-390.

[9] Kasaba T, Yamaga M, Iwasaki T, Yoshimura Y, Takasaki M. Ephedrine, dopamine, or dobutamine to treat hypotension with propofol during epidural anesthesia. Canadian Journal of Anesthesia 2000;47(3):237-241.

[10] Chiu CL, Tew GP and Wang CY. The effect of prophylactic metaraminol on systemic hypotension caused by induction of anesthesia with propofol in patients over 55 years old. Anaesthesia 2001;56:893-896.

[11] Turner RJ, Gatt SP, Kam PCA, Ramzan I, Daley M. Administration of a crystalloid fluid preload does not prevent the decrease in arterial blood pressure after induction of anesthesia with propofol and fentanyl. British Journal of Anesthesia 1998;80:737-741

[12] Kumar M, Saxena N and Saxena AK. The effect of a colloid or crystalloid preload on hypotension caused by induction of anesthesia with propofol and fentanyl. Journal of Anesthesia and Clinical Pharmacology 2008;24(4):409-412. 
[13] Gauss A, Heinrich H, Wilder-Smith OH. Echocardiographic assessment of the hemodynamic effects of propofol: a comparison with etomidate and thiopentone. Anaesthesia 1991;46:99-105.

[14] Bennett GM and Stanley TH. Cardiovascular effects of fentanyl during enflurane anesthesia in man. Anesthesia and Analgesia 1979;58:179-182.

[15] Al-Ghamdi A. Hydroxyethylstarch 6\% preload does not prevent the hypotension following induction with propofol and fentanyl. Middle East Journal of Anesthesiology 2004;17(5):959-968.

[16] Dhungana Y, Bhattarai BK, Bhadani UK, Biswas BK and Tripathi M. Prevention of hypotension during propofol induction: A comparison of preloading with 3.5\% polymers of degraded gelatin (Haemaccel) and intravenous ephedrine. Nepal Medical College Journal 2008;10(1):16-19.

[17] Michelsen I, Helbo-Hansen HS, Kohler F, Lorenzen AG, Rydlund E, Bentzon MW. Prophylactic ephedrine attenuates the hemodynamic response to propofol in elderly female patients. Anesthesia and Analgesia 1998;86:477-481.

[18] Gamlin F, Vucevic M, Winslow L, Berridge J. The hemodynamic effects of propofol in combination with ephedrine. Anaesthesia 1996;51(5):488-491.

[19] El-Beheiry H, Kim J, Milne B, Seegobin R. Prophylaxis against the systemic hypotension induced by propofol during rapidsequence intubation. Canadian Journal of Anesthesia 1995;42(10):875-878.

[20] Chitchley LAH, Stuart JC, Conway F, Short TG. Hypotension during subarachnoid anesthesia: Hemodynamic effects of ephedrine. British Journal of Anesthesia 1995;74:373-378.

[21] Claeys MA, Gepts E, Camu F. Haemodynamic changes during anesthesia induced and maintained with propofol. British Journal of anesthesia 1988;60:3-9.

[22] Gamlin F, Freeman J, Winslow L, Berridge J, Vucevic M. The hemodynamic effects of propofol in combination with ephedrine in elderly patients (ASA groups 3 and 4). Anesthesia and Intensive Care 1999;27(5):477-480. 